\title{
Column Leaching Tests to Valorize a Solid Waste from the Decommissioning of Coal-Fired Power Plants
}

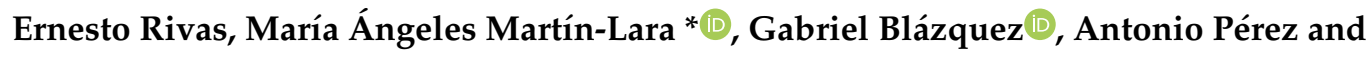 \\ Mónica Calero \\ Chemical Engineering Department, University of Granada, 18071 Granada, Spain; \\ ernestorivas@hotmail.es (E.R.); gblazque@ugr.es (G.B.); aperezm@ugr.es (A.P.); mcaleroh@ugr.es (M.C.) \\ * Correspondence: marianml@ugr.es; Tel.: +34-958240445
}

Received: 6 April 2019; Accepted: 30 April 2019; Published: 4 May 2019

\begin{abstract}
Solid waste from the decommissioning of coal-fired power plants collected from a power plant in Spain (Puertollano, Ciudad Real) was subjected to acid leaching tests in columns to evaluate the leachability of several valuable and toxic metals ( $\mathrm{Al}, \mathrm{Ca}, \mathrm{Fe}, \mathrm{K}, \mathrm{Mg}, \mathrm{Na}, \mathrm{Ti}, \mathrm{V}, \mathrm{Cr}, \mathrm{Mn}, \mathrm{Ni}$, and $\mathrm{Zn}$ ). First, the contaminated waste, delivered by a national company, was chemically characterized. Second, column-leaching tests were conducted using two different acid solutions (nitric and sulfuric acid). The effect of the leaching agent concentration and time of leaching were examined. The results of column leaching tests showed that different concentrations of the acid solutions leached different proportions of $\mathrm{Al}, \mathrm{Fe}, \mathrm{Mg}, \mathrm{Mn}, \mathrm{Ni}, \mathrm{V}$, and $\mathrm{Zn}$, which were leached by acid solutions from the solid waste sample. In general, use of sulfuric acid at $\mathrm{pH} 0.5$ resulted in better leaching. Next, a comparison between three different configurations (one single stage without recirculation, one single stage with total recirculation of leachate and leaching in two consecutive stages: one with total recirculation of leachate and another one with acid set to a $\mathrm{pH}$ value of 0.5 and without recirculation) was performed. At the end of the experiments, all leaching methods resulted in comparable yields for $\mathrm{Al}(0.36-0.48 \%)$, Fe (5.99-6.40\%), Mg (4.43-5.11\%), Mn (2.71-2.83\%), Ni (12.08-12.75\%), V (0.08-0.34\%), and Zn (23.62-25.28\%). However, better results were obtained when two consecutive stages were carried out. Additionally, the effect of forced aeration on leachability was studied. Finally, this investigation showed that hydrometallurgical treatment of contaminated solid by means of acid leaching followed by basic leaching and a water wash between these stages was a potentially feasible method for reducing hazardous levels of the residue.
\end{abstract}

Keywords: acid leaching; coal-fired power plants; column systems; metals; sulfuric acid; waste processing

\section{Introduction}

Coal is used worldwide to generate electricity. In Spain, as in many other countries around the world, coal accounts for an important percentage of total electricity production [1]. Coal-fired power plants currently produce $37 \%$ of global electricity and, in some countries, the percentage is even higher [2]. Despite some significant uncertainties, there is a reasonable degree of consensus on the energy outlook for the future. Experts agree that future energy system will not look like todays. The development of renewables energies will change the world's electricity mix and many coal-fired power plants will be completely decommissioned [3-5].

Although the decommissioning of nuclear power plants has been extensively studied [6-13], far less research has been done to examine the decommissioning of coal, oil, and natural gas-burning plants $[4,14]$. 
There is a great of attention in increasing techniques capable of recovering and stabilizing solid waste derived from the decommissioning of coal power plants. In general, when coal-fired power plants are removed from service, diverse types of waste are collected and stored together (mainly bottom and fly ashes, non-used carbon). This causes an environmental risk but also involves a loss of metals such as aluminum, magnesium, vanadium, or zinc.

The main technologies for the recovery of metals from solid are hydrometallurgical processes. Hydrometallurgy is a technique used to extract metals from mineral solids by leaching with liquid solvents. It involves the use of chemical reactions in aqueous or organic solutions [15]. It is the most highly developed technology due to: (1) safe disposal of precipitates and eluates; (2) significant and easy recovery of metals; (3) relatively low energy requirement; 4) easy implementation at laboratory scale for testing new processes and materials; (5) relatively low capital investment and operating costs $[16,17]$. Several studies have investigated hydrometallurgy processes by using strong mineral acids $\left(\mathrm{HCl}, \mathrm{HNO}_{3}\right.$, and $\left.\mathrm{H}_{2} \mathrm{SO}_{4}\right)$ for leaching of heavy metals from various solids such as soil, sludge, electronic waste, fly ash, etc. [18-21]. Low $\mathrm{pH}$ obtained with the strong mineral acids resulted in high metal removal efficiencies. For example, Brunori et al. [18] performed an evaluation of five different leaching/extraction tests. These authors analyzed the effect of parameters such as the liquid-solid ratio, $\mathrm{pH}$, leaching agent, stirring conditions, and extraction time on metal extraction efficiencies of a fly ash. The results show $\mathrm{pH}$ value has the highest impact on metal release. Also, Komonweeraket et al. [19] examined the influence of $\mathrm{pH}$ on the leaching of metals from fly ash mixed with soil. They focus on understanding leaching controlling mechanisms of metals. The leaching of metals such as aluminum, chromium, copper, iron, and zinc increased at very low or high $\mathrm{pH}$ values. Yang et al. [20] studied the removal of aluminum from the diamond wire saw powder by $\mathrm{HCl}$ leaching method. These authors also studied the effect of operating conditions such as the concentration of $\mathrm{HCl}$, the leaching temperature, the reaction time, and the liquid-solid ratio in the extraction efficiency. Finally, Kumar et al. [21] studied the leaching performance of the bottom ash of thermal power plants. Authors observed that $\mathrm{Cr}, \mathrm{Cu}, \mathrm{Mg}, \mathrm{Mn}, \mathrm{Ni}$, and $\mathrm{Zn}$ were the most abundant elements on this solid. They also observed a high dependence of extraction with $\mathrm{pH}$ and the liquid-solid ratio. Other alternatives, including bioleaching, have been also investigated [22-24]. However, bioleaching still requires process optimization in order to improve its efficiency and economics.

Although a great amount of literature was focused on the leaching of solid waste by using strong mineral acids, the majority of literature studies associated with treatment of solid waste derived from coal-fired power plants focuses only on the leaching of metals from flying and bottom ashes. Only a few studies have focused on the leaching behavior of elements from environmental samples that are mixtures [25,26]. In addition, most studies are performed in batch systems [27-29] and only a few researches focused on the dynamics of leaching process in columns. Chichester and Landsberger [30] analyzed the extraction of thirty-three elements present in fly ash from municipal solid waste incinerators. They performed tests on fixed bed columns using deionized water as a leaching agent. It was found that almost all the elements initially present in the solid were rapidly extracted and then decreased to almost constant concentrations after five volumes of pores of water passed through the column.

In this context, the acid leaching behavior of a solid mixture waste from an out of operation coal-fired power plant in Puertollano, Ciudad Real (Spain) was analyzed. The main purpose of this work was to develop procedures of metal recovering from solid waste derived from decommissioning coal-fired power plants and stabilizing the final residual solids. Particularly, the work investigates the efficiency of column leaching using different leaching configurations as well as studying the effect of (1) the re-set of $\mathrm{pH}$ of leaching agent during operation and (2) the addition of forced aeration during the leaching on the overall efficiency of the process. The results could help us better understand the potential leaching risk for these mixed solid residues derived from the decommissioning of coal-fired power plants and could provide scientific support for the proper metal recovery and chemical stabilization. 


\section{Materials and Methods}

\subsection{Sample and Sampling}

The material examined in this study was industrial waste from a coal-fired power plant in Puertollano, Ciudad Real (Spain). The original waste was a mixture of flying and bottom ashes, coal, coke, and soil with a particle size between 0 and $8 \mathrm{~mm}$. In order to ensure the representativeness of the sample, the sampling has been carried out in accordance with the UNE EN 14899: 2007 standard. The material was mostly black with some yellow particles, formed by elemental sulfur. The collected primary sample was oven dried at a low temperature $\left(60^{\circ} \mathrm{C}\right)$ for $48 \mathrm{~h}$ before being used in the experiments. A complete characterization of this residual waste was previously reported by Rivas et al. [26]. The moisture content analysis was made based on weight loss after drying at $105^{\circ} \mathrm{C}$ during $24 \mathrm{~h}$. For the determination of the particle size distribution, a screening method was carried out using standardized ASTM sieves. The elemental analysis was performed by means of an elemental analyzer from Fisons company (model 1108). The ash analysis was carried out according to the procedure described in ISO 18122:2015. Finally, methods for the determination of major, minor, and trace elements of solids were carried out. The solid was firstly digested and analyzed by inductively coupled plasma-optical emission spectrometry (ICP-OES) and inductively coupled plasma-mass spectrometry (ICP-MS).

\subsection{Pre-Washing of Sample}

The solid was washed with distilled water before the leaching step. The objective was to eliminate water-soluble salts and increase the efficiency of acid leaching [31]. The washing procedure was repeated three times at room temperature with a liquid-solid ratio of 10 . This has been found to sufficiently dissolve most water soluble salts. Solid and liquid (washing water) were separated using a centrifuge, and then the washed solid was dried at $60^{\circ} \mathrm{C}$ for $48 \mathrm{~h}$.

\subsection{Acid Leaching Tests in Columns}

To investigate the leaching efficiency of different metal species, a PVC (polyvinyl chloride) column with a length of $50 \mathrm{~cm}$ and an inner diameter of $10 \mathrm{~cm}$ was used. About $10 \mathrm{~kg}$ of homogeneous contaminated waste was packed into a column (the packing density was $707.4 \mathrm{~kg} / \mathrm{m}^{3}$ ) and leached continuously with acid leaching solution at a controlled flow rate of $180 \mathrm{~mL} / \mathrm{min}$ and in upflow mode. An overflow in the top of the column allowed the leachate to be re-collected, and a valve at the bottom released the liquid in the column when the process finished. Because high temperatures do not significantly improve leaching kinetics and yields in acid leaching [32], the reactor was operated at room temperature.

The column was designed with the possibility of incorporating air in the bottom of the column. Some new experimental tests were performed to study the effect of an assistant agent (forced aeration) on extraction efficiencies. The air entry was regulated with a gas rotameter between the compressor and the bottom of the column. In experiments performed with aeration, an airflow rate of $1.67 \mathrm{~L} / \mathrm{min}$ was used.

First, leaching tests were carried out to determine the best acid leaching agent and its concentration (in terms of $\mathrm{pH}$ value of solution). Six acid leaching solutions were used: Leaching agent $\mathrm{A}, 0.3 \mathrm{M}$ sulfuric acid ( $\mathrm{pH} 0.5$ ); leaching agent $\mathrm{B}, 0.1 \mathrm{M}$ sulfuric acid ( $\mathrm{pH}$ 1); leaching agent $\mathrm{C}, 0.01 \mathrm{M}$ sulfuric acid ( $\mathrm{pH}$ 2); leaching agent $\mathrm{D}, 0.3 \mathrm{M}$ nitric acid ( $\mathrm{pH} 0.5$ ), leaching agent $\mathrm{E}, 0.1 \mathrm{M}$ nitric acid ( $\mathrm{pH}$ 1), leaching acid F, $0.01 \mathrm{M}$ nitric acid ( $\mathrm{pH}$ 2). These solutions were prepared using analytical grade reagents. A pH meter was then used to measure the $\mathrm{pH}$ within 0.05 of the desired unit. Different operation times were studied until constant leaching was achieved. Then, when the best acid solution and operating conditions were established, a test with total recirculation of the leachate was implemented to study the impact of the recirculation on metal recovery (see Figure 1a). In this experiment, a total volume of acid solution of $10 \mathrm{~L}$ was fixed. Finally, a procedure in two consecutive stages was studied. When steady 
state in metals concentration in the liquid was achieved (stage of total recirculation), the flux diagram changes, as is show in Figure 1b. In the second operating stage, all the liquid that passed through the column was the same acid solution but set to a $\mathrm{pH}$ value of 0.5 and without recirculation.

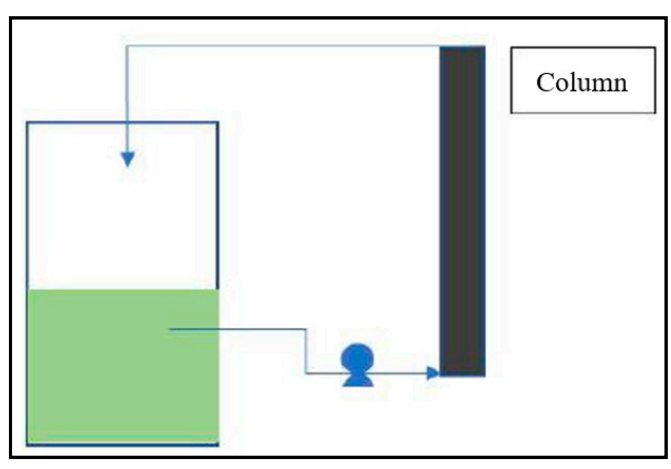

(a)

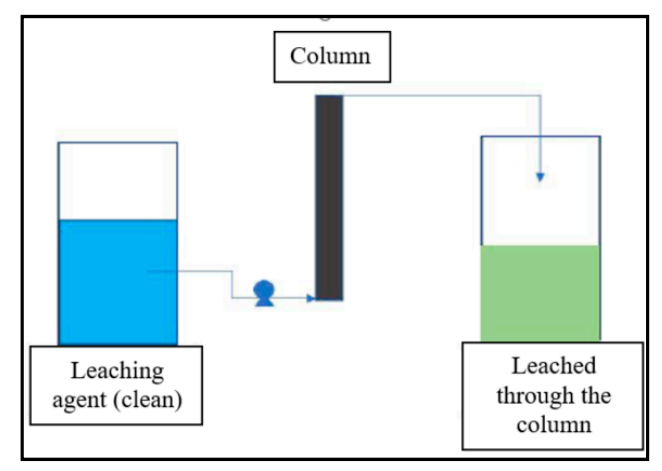

(b)

Figure 1. (a) Operation scheme of stage with total recirculation of leachate; (b) Operation scheme of stage without recirculation.

In all column tests, leachate samples were collected regularly every $5 \mathrm{~min}$. A small subsample of the leachates was immediately analyzed for its $\mathrm{pH}$ value, while the rest were analyzed by means of inductively coupled plasma mass spectrometry (ICP-MS). The final solid was poured into reactors in order to again analyze its leaching behavior and its eligibility to be stored in inert landfill sites.

\subsection{Analysis of Elution Stability after Column Leaching Tests}

To measure the elution stability of residual solid after the metal extraction, the standard UNE-EN 12457-4 was applied. $90 \mathrm{~g}$ were putted in a glass container with $900 \mathrm{~mL}$ of distillated water to keep a liquid-solid ratio of 10 . The glass container was shaken using a rotatory shaker model, R4-H DE Rotator HD from OVAN ${ }^{\circledR}$ (Barcelona, Spain), at $10 \mathrm{rpm}$ for $24 \mathrm{~h}$. When the extraction time was finished, the eluate was filtered in a porous plate using a vacuum pump and a filter with $45 \mu \mathrm{m}$ diameter pores and analyzed by means of ICP-MS.

\subsection{Treatment for Obtaining an Inert Solid}

To achieve the inertization of residual material (after acid leaching tests), the following process was completed in dynamic mode in columns:

- 1st stage: An acid solution of $0.3 \mathrm{M}$ sulfuric acid at $\mathrm{pH}$ value of 0.5 was pumped through the column. $10 \mathrm{~L}$ of solution was distributed through the column at constant flow rate over $120 \mathrm{~min}$.

- stage: $10 \mathrm{~L}$ of water was distributed through the column at constant flow rate over $120 \mathrm{~min}$.

- stage: A basic solution of $0.1 \mathrm{M} \mathrm{NaOH}$ at $\mathrm{pH}$ value of 13 was pumped through the column. $10 \mathrm{~L}$ of solution was distributed through the column at constant flow rate over $120 \mathrm{~min}$.

- stage: $10 \mathrm{~L}$ of water was distributed through the column at constant flow rate over $120 \mathrm{~min}$.

To measure the elution stability of residual solid after the inertization process, the standard UNE-EN 12457-4 was applied as was explained in Section 2.3.

\section{Results}

\subsection{Characterization of Solid Waste}

The chemical composition of solid waste examined in this study is given in Table 1. Standard deviation (SD) was calculated from three different samples collected as was indicated in Section 2.1. Only majority elements and elements with high toxicity were included in Table 1. A complete 
characterization of this residual waste was previously reported by Rivas et al. [26] as it was described before. The sample had a relatively high metal pollution. For example, sample content of $\mathrm{Cr}$, $\mathrm{Ti}$, and $\mathrm{V}$ was 1951, 3656, and $1954 \mathrm{mg} / \mathrm{kg}$, respectively. Also, significant concentrations of $\mathrm{Mn}, \mathrm{Ni}$, and Zn were observed with values of 416,195 , and $78 \mathrm{mg} / \mathrm{kg}$, respectively. In addition, high contents of $\mathrm{Al}, \mathrm{Ca}, \mathrm{Fe}$, $\mathrm{K}, \mathrm{Mg}$, and $\mathrm{Na}$ were detected. Due to logistical reasons, about $100 \mathrm{~kg}$ of primary sample was collected. The standard deviations values for most of the major elements fall within a narrow range, suggesting a relatively homogeneous sample of material.

With respect to particle size distribution (data not reported in Table 1), only 15\% of the samples presented a particle size below $0.25 \mathrm{~mm}$. About $49 \%$ of samples had a particle size between 0.5 and $2 \mathrm{~mm}$ and more than $11 \%$ showed a particle size higher than $2 \mathrm{~mm}$.

Table 1. Major chemical composition and toxic metals contents of original contaminated waste.

\begin{tabular}{|c|c|c|c|}
\hline Parameter & & Average & Standard Deviation, SD \\
\hline \multirow{4}{*}{ Elemental analysis, \% } & $\mathrm{C}$ & 4.32 & 0.28 \\
\hline & $\mathrm{H}$ & 0.12 & 0.02 \\
\hline & $\mathrm{N}$ & 0.00 & 0.01 \\
\hline & $S$ & 2.03 & 0.16 \\
\hline Ash content, $\%$ & & 92.30 & 2.31 \\
\hline \multirow{12}{*}{$\begin{array}{l}\text { Major elements and toxic } \\
\text { metals content, } \mathrm{mg} / \mathrm{kg}\end{array}$} & $\mathrm{Al}$ & 108600 & 8500 \\
\hline & $\mathrm{Ca}$ & 45000 & 4120 \\
\hline & $\mathrm{Fe}$ & 34640 & 3910 \\
\hline & $\mathrm{K}$ & 15500 & 1844 \\
\hline & $\mathrm{Mg}$ & 5558 & 584 \\
\hline & $\mathrm{Na}$ & 4222 & 470 \\
\hline & $\mathrm{Ti}$ & 3656 & 390 \\
\hline & $\mathrm{V}$ & 1954 & 260 \\
\hline & $\mathrm{Cr}$ & 1951 & 134 \\
\hline & Mn & 416 & 48.1 \\
\hline & $\mathrm{Ni}$ & 195 & 12.4 \\
\hline & $\mathrm{Zn}$ & 78 & 7.61 \\
\hline
\end{tabular}

\subsection{Column Leaching Tests}

\subsubsection{Effect of Pre-Washing}

High contents of chloride and mineral salts such as $\mathrm{Ca}, \mathrm{K}$, and $\mathrm{Na}$ are typically removed by washing [33]. The results showed that pre-washing the solid removed most water-soluble salts and some sulfur. More than $50 \%$ of the $\mathrm{Ca}, \mathrm{K}$, and $\mathrm{Na}$ and $10 \%$ of the sulfur were removed. A calcium content of $2880 \mathrm{mg} / \mathrm{L}$ was found in the water after pretreatment. Similarly, 884, 249, and $1056 \mathrm{mg} / \mathrm{L}$ concentrations of $\mathrm{K}, \mathrm{Na}$, and sulfur were detected in water, respectively. These results are in agreement with previous published works [33,34]. For example, Funari et al. [33] found removal of more than $80 \%$ for $\mathrm{Cl}, \mathrm{K}$, and $\mathrm{Na}$ when they washed municipal solid waste incineration fly ashes.

\subsubsection{Study of Metal Leaching as a Function of Acid Leaching Agent and Leaching Conditions}

For every acid leaching agent, leaching conditions, including leaching solution $\mathrm{pH}$ and operation time, can influence metal removal $[35,36]$. Figure 2 shows the concentrations of metal removal for different leaching agents as a function of time. Chemical leaching removed all major elements, such as $\mathrm{Al}, \mathrm{Fe}$, and $\mathrm{Mg}$, and other minor elements such as $\mathrm{Mn}, \mathrm{Ni}, \mathrm{V}$, or Zn. For the same acid leaching agent, the concentrations of leaching metals increased with decreasing pH (acidification). This could 
be because decomposition of sample structure at strongly low $\mathrm{pH}$ is produced. Also, to a lesser extent, $\mathrm{H}^{+}$ions could compete for the adsorption sites with the metal ions, influencing the exchange adsorption of heavy metals [36]. Other researchers also published that concentration of $\mathrm{Al}, \mathrm{Fe}, \mathrm{Mg}$, $\mathrm{Mn}, \mathrm{Ni}, \mathrm{V}$, and $\mathrm{Zn}$ released were greatly increased at low $\mathrm{pH}$ conditions $[19,34,37]$. For example, Komonweeraket et al. [19] studied the extraction of $\mathrm{Al}, \mathrm{Cr}, \mathrm{Fe}, \mathrm{Cu}, \mathrm{Mn}$, and $\mathrm{Zn}$ from Maryland soil-fly ash mixtures and fly ashes at three different $\mathrm{pH}$ conditions and obtained that the leaching was higher at low $\mathrm{pH}$ conditions. In addition, between the two acid leaching agents analyzed, sulfuric acid seems to present a better behavior. Hence, sulfuric acid with a $\mathrm{pH}$ of 0.5 was used as the optimal leaching agent for the following column leaching studies. Operation time was approximately $80 \mathrm{~min}$; after this time no significant change in concentration of metal was detected in the leachate. Therefore, metal removal generally reached stability in approximately $80 \mathrm{~min}$.

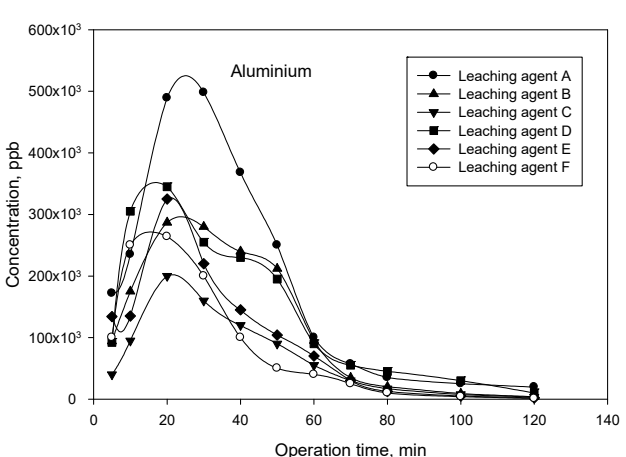

(a)

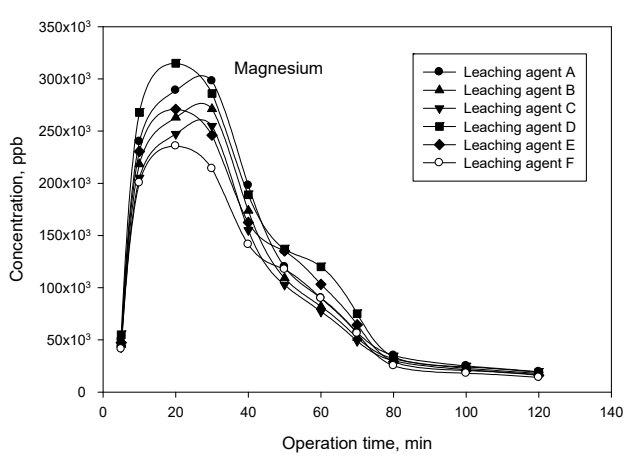

(c)

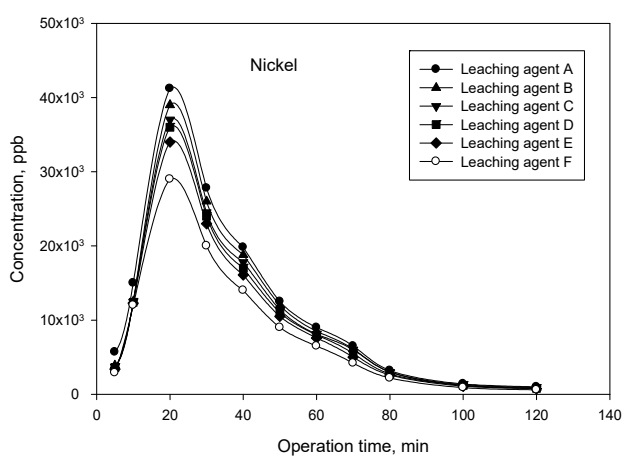

(e)

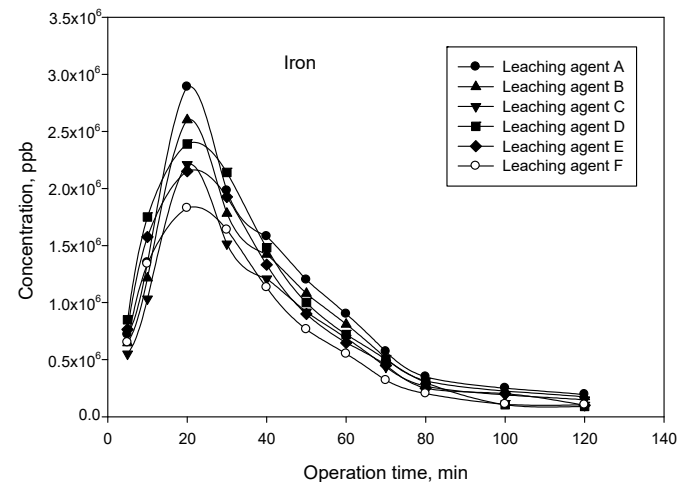

(b)

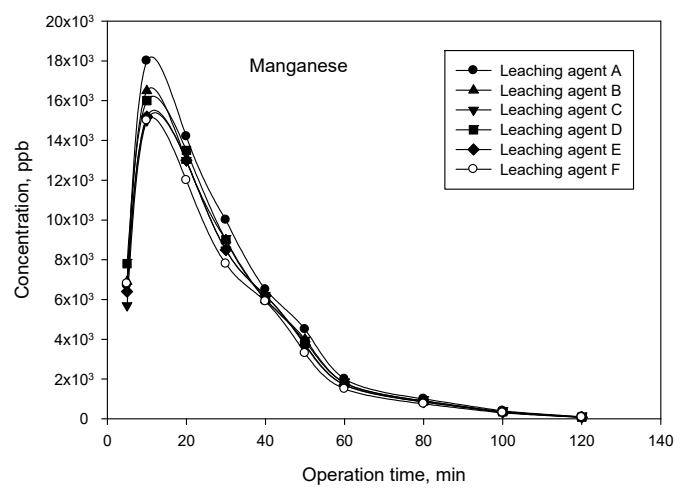

(d)

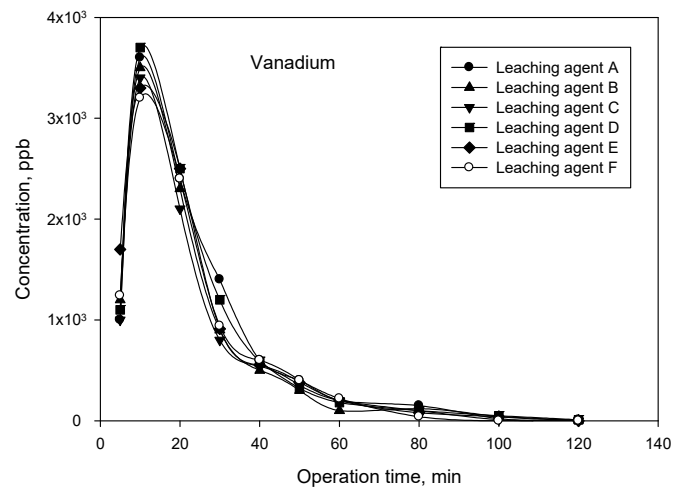

(f)

Figure 2. Cont. 


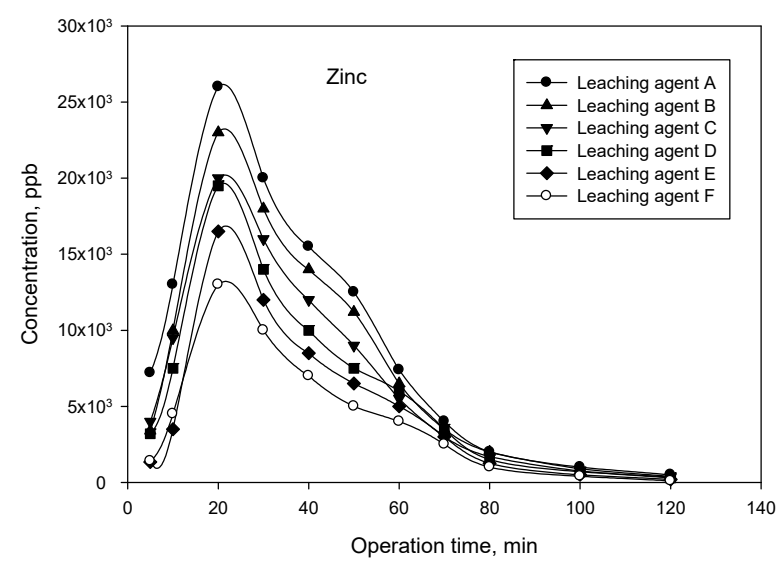

(g)

Figure 2. Concentrations of metal removal for different leaching agents in function of time, (a) aluminum, (b) iron, (c) magnesium, (d) manganese, (e) nickel, (f) vanadium, (g) zinc.

\subsubsection{Study of Metal Leaching in Different Column Operating Modes}

For a comparison between different operating modes, a column leaching test with total recirculation of leachate was implemented and compared with the results of an experiment performed without recirculation. Figure 3 shows solution $\mathrm{pH}$ trends (Figure 3a) and concentrations (Figure 3b) of elements released during the column leaching test of the solid waste under total recirculation of leachate. After $120 \mathrm{~min}$ of sulfuric acid leaching, the solution $\mathrm{pH}$ varied from 0.5 to 1.0. Similar curves for the leached concentration of studied elements, with varying leaching time, can be identified in the leaching tests. A sharp increase followed by a steady curve was the major trend in tests performed under total recirculation. The concentration was decreased by the dilution of the elements with the rest of the leaching agent that was contained in the tank. It showed higher extractable concentrations of the studied elements in the initial leaching phase but decreased gradually with leaching time until it reached a constant value of 39,500, 2,090,000, 259,110, 11,275, 23,538, 2780, and 19,062 ppb for Al, Fe, $\mathrm{Mg}, \mathrm{Mn}, \mathrm{Ni}, \mathrm{V}$, and $\mathrm{Zn}$, respectively. Furthermore, results indicated that the leaching process under recirculation was also fast, because after approximately $60 \mathrm{~min}$, steady state was reached and no more leaching time was needed.

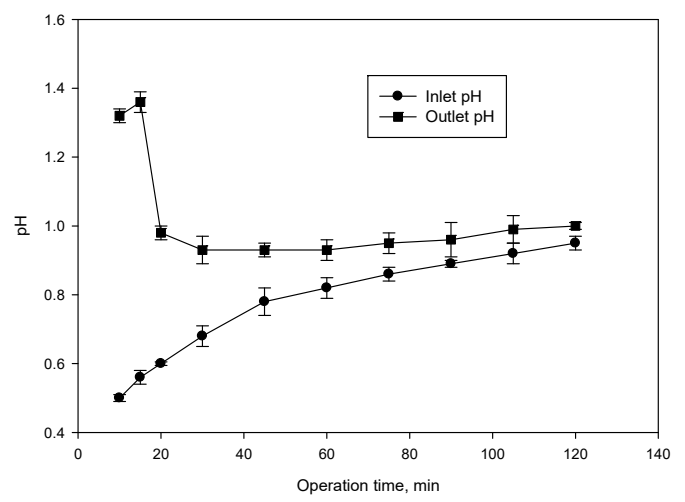

(a)

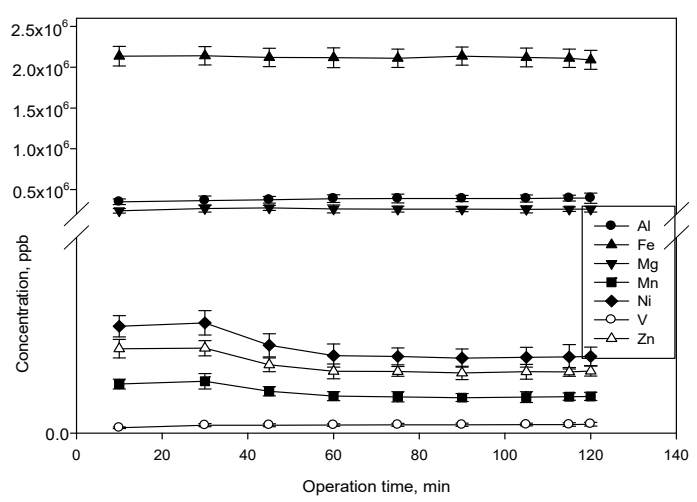

(b)

Figure 3. Solution $\mathrm{pH}$ trends (a) and concentrations (b) of elements released during column leaching test of the solid waste under total recirculation of leachate. 
The following equation was used to analyze the leaching behavior of the solid during different operation designs.

$$
\mathrm{L}(\%)=\frac{\mathrm{C}_{1} \cdot \mathrm{V}}{\mathrm{C}_{\mathrm{s}} \cdot \mathrm{M}} \cdot 100
$$

where L is the leachability or extraction efficiency (expressed as percentage), $C_{1}$ is the element concentration in leaching solution, $C_{S}$ is the element concentration in solid sample, $V$ is the volume of the resulting leachate, and $\mathrm{M}$ is the total mass of solid sample.

Table 2 reports extraction efficiencies as a function of time for main leachable elements. According to the results, relatively low extraction efficiencies of elements, such as $\mathrm{Al}, \mathrm{Fe}, \mathrm{Mg}, \mathrm{Mn}, \mathrm{Ni}, \mathrm{V}$, or $\mathrm{Zn}$ were achieved. These results differ from those published by other authors that found extraction efficiencies of more than $70 \%$ for these same elements [33]. This might be because the properties and structures of these metal-bearing minerals are less susceptible to sulfuric acid and are impacted by the larger particle size of material. Most published works use smaller particle sizes than those used in this study. However, in this study, the raw material was preferred.

Table 2. Leachability or extraction efficiency in different column configurations (\%): (1) one single stage without recirculation; (2) one single stage with total recirculation of leachate; (3) leaching in two consecutive stages (one with total recirculation of leachate and the another one with re-set of leachate at $\mathrm{pH} 0.5$ and without recirculation).

\begin{tabular}{ccccccccc}
\hline \multirow{2}{*}{ Column Configuration } & \multicolumn{7}{c}{ Extraction Efficiency, \% } \\
\cline { 2 - 9 } & $\mathbf{A l}$ & $\mathbf{F e}$ & $\mathbf{M g}$ & $\mathbf{M n}$ & $\mathbf{N i}$ & $\mathbf{V}$ & $\mathbf{Z n}$ \\
\hline \multirow{2}{*}{$\begin{array}{c}\text { One single } \\
\text { stage-Without } \\
\text { recirculation }\end{array}$} & 0.16 & 2.64 & 2.04 & 1.49 & 6.26 & 0.06 & 10.96 \\
\cline { 2 - 9 } & $\mathbf{6 0} \mathrm{min}$ & 0.31 & 4.83 & 3.70 & 2.22 & 10.94 & 0.07 & 20.58 \\
\hline & $90 \mathrm{~min}$ & 0.34 & 5.76 & 4.28 & 2.41 & 12.53 & 0.08 & 23.27 \\
\hline $\begin{array}{c}\text { One single stage-With total } \\
\text { recirculation (at stationary state) }\end{array}$ & 0.36 & 6.04 & 4.66 & 2.71 & 12.08 & 0.14 & 24.41 \\
\hline \multicolumn{2}{c}{ Two consecutive stages } & 0.48 & 6.40 & 5.11 & 2.83 & 12.64 & 0.34 & 25.28 \\
\hline
\end{tabular}

Similar results were achieved working in the two configurations; however, it is important to note that for the determination of leachability in the experiment without recirculation, a numeric integral was developed, and some error could be associated with calculated values.

Finally, because solution $\mathrm{pH}$ is one of the important factors affecting the leaching behavior of metals $[19,34,38]$, the impact of change in $\mathrm{pH}$ on the leaching behavior of the elements was investigated in the following way. After a first stage of acid leaching with total recirculation of leachate for $120 \mathrm{~min}$ (this time is sufficient to reach a steady state), the leachate was set at $\mathrm{pH}=0.5$ and added in continuous mode. As Figure 4 shows, for most of the elements, the addition of a second stage with leachate re-set at $\mathrm{pH} 0.5$ had little impact; however, in general, a small increase in concentration of leachate was observed. This indicated a dependence of metals leaching on $\mathrm{pH}$ as it was reported previously by other researchers [19,34,39]. For example, Wang et al. [34] proved $\mathrm{pH}$ values ranged from 3.0 to 6.0 to simulate the exposure conditions for fly ashes in landfills. At low $\mathrm{pH}$ values, the concentration of $\mathrm{Zn}$ released from fly ash samples was increased. These authors explained that it could be due to an increase of dissolution of mineral phase at low $\mathrm{pH}$ conditions. In Table 2, extraction efficiency of this new procedure was also included. The results of this study indicate a slight increase in efficiency in comparison to the results of previous experiments. 


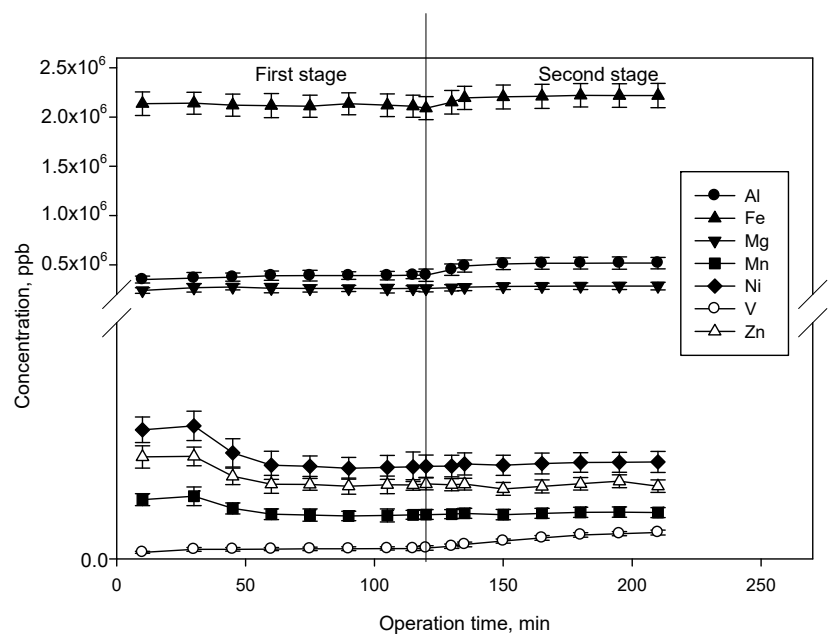

Figure 4. Concentrations of elements released during column leaching test of the solid waste first under total recirculation of leachate (first stage) and then with leachate re-set at $\mathrm{pH} 0.5$ (second stage).

\subsubsection{Effect of an Assistant Agent (Forced Aeration) on Extraction Efficiencies}

To analyze the effect of forced aeration (assistant agent) on leachability, tests were performed under forced aeration in configuration that included two stages (one with total recirculation of leachate and another one with $\mathrm{pH}$ of 0.5 in dynamic mode). This configuration was chosen because it was the arrangement that resulted in the most efficient extraction. The benefit of forced aeration for leaching is summarized in Figure 5. The results from forced aerated column tests were better than those of non-aerated columns. Forced aeration improved the concentration of all studied metals and, consequently, the level of recovery of these elements. In addition, concentration of metals, such as vanadium or zinc, also increased increased after an initial decrease due to dilution with the leaching agent presented in the tank. Table 3 reports extraction efficiencies for the main leachable elements under forced aeration operation in two different column configurations. A significant increase in extraction efficiency for $\mathrm{Zn}$ under forced aeration is observed. Specifically, for leaching in two consecutive stages, the extraction efficiency for $\mathrm{Zn}$ increases from 25.28 to $60.03 \%$. Also, extraction yields of iron and vanadium increased to $2.83 \%$ and $9.29 \%$, respectively.

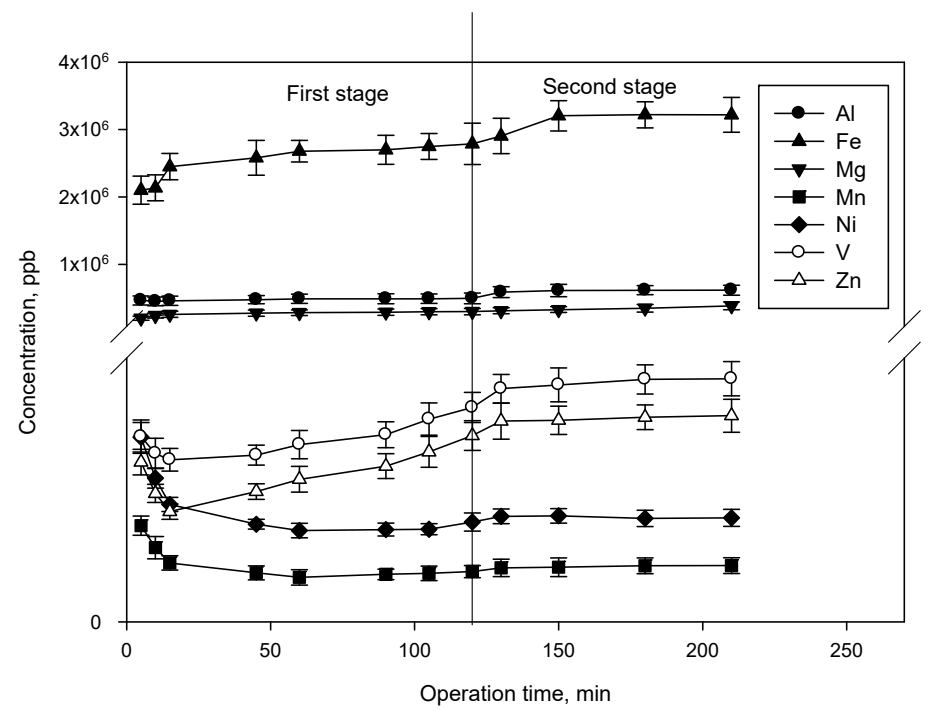

Figure 5. Concentrations of elements released during column leaching test of the solid waste, first under total recirculation of leachate (first stage) and then with leachate re-set at $\mathrm{pH} 0.5$ (second stage) in tests performed under forced aeration. 
Table 3. Leachability or extraction efficiency in different column configurations under forced aeration (\%): (1) one single stage with total recirculation of leachate; (2) leaching in two consecutive stages (one with total recirculation of leachate and another one with re-set of leachate at $\mathrm{pH} 0.5$ and without recirculation).

\begin{tabular}{cccccccc}
\hline \multirow{2}{*}{ Column Configuration } & \multicolumn{7}{c}{ Extraction Efficiency, \% } \\
\cline { 2 - 8 } & $\mathbf{A l}$ & $\mathbf{F e}$ & $\mathbf{M g}$ & $\mathbf{M n}$ & $\mathbf{N i}$ & $\mathbf{V}$ & $\mathbf{Z n}$ \\
\hline $\begin{array}{c}\text { One single stage-With total } \\
\text { recirculation(at stationary state) }\end{array}$ & 0.46 & 8.05 & 5.38 & 2.75 & 11.66 & 2.49 & 54.24 \\
\hline Two consecutive stages & 0.57 & 9.29 & 6.91 & 3.08 & 12.13 & 2.83 & 60.03 \\
\hline
\end{tabular}

The improvement in the results may be due to the fact that the air bubbles ascending through the column produces enough agitation to improve the mass transfer inside the column and improve the hydraulic behavior. Also, the forced aeration can promote the development of the porous structures of the solid and help to break the blocked pathways of the solution, improving the yield of the leaching.

\subsection{Elution Stability after Leaching Tests}

When remediating metal-contaminated waste via the leaching technique, it is important to study the properties of the waste. Table 4 shows the values of residual metals of the final solid derived from acid leaching treatments and of the solid before treatment. After the acid leaching, the leachability of residual metals was significantly reduced in comparison to that of the original contaminated waste. However, it should be noted that $\mathrm{Sb}$ concentration was substantially higher than the legal limit for landfill in inert landfill sites according the Spanish order AAA/661/2013.

Table 4. Concentration of leaching elements in solids according to standard UNE-EN 12457-4 (data reported in $\mathrm{mg} / \mathrm{kg}$ ).

\begin{tabular}{ccccc}
\hline Element & $\begin{array}{c}\text { Before Acid Leaching (Original } \\
\text { Contaminated Waste) }\end{array}$ & $\begin{array}{c}\text { After Acid } \\
\text { Leaching }\end{array}$ & $\begin{array}{c}\text { Complete Leaching } \\
\text { Treatment }\end{array}$ & $\begin{array}{c}\text { Limit Values for } \\
\text { Inert Landfill }\end{array}$ \\
\hline $\mathrm{As}$ & 0.02 & 0.02 & 0.01 & 0.5 \\
\hline $\mathrm{Ba}$ & 0.26 & 0.05 & 0.04 & 20 \\
\hline $\mathrm{Cd}$ & 0.06 & 0.00 & 0.00 & 0.04 \\
\hline $\mathrm{Cr}$ & 0.00 & 0.01 & 0.01 & 0.5 \\
\hline $\mathrm{Cu}$ & 0.12 & 0.01 & 0.01 & 0.01 \\
\hline $\mathrm{Hg}$ & 0.07 & 0.07 & 0.01 & 0.5 \\
\hline $\mathrm{Mo}$ & 0.01 & 0.02 & 0.01 & 0.4 \\
\hline $\mathrm{Ni}$ & 26.53 & 0.02 & 0.02 & 0.5 \\
\hline $\mathrm{Pb}$ & 0.03 & 0.02 & 0.01 & 0.06 \\
\hline $\mathrm{Sb}$ & 0.13 & 0.12 & 0.05 & 0.1 \\
\hline $\mathrm{Se}$ & 0.02 & 0.04 & 0.00 & 4 \\
\hline $\mathrm{Zn}$ & 19.29 & 0.09 & 0.08 & 2 \\
\hline
\end{tabular}

Therefore, final residues need further processing in order to achieve inert landfill status. According to results, metals remaining in the final leaching residue are very stable and cannot be extracted under strong acid conditions. In general, this fraction must be treated in a sequential leaching process [37]. Therefore, a treatment procedure for obtaining an inert solid was proposed, including acid and basic leaching with washing stages between them (as was explained in Section 2.4). Results showed that this proposed treatment procedure was very effective in stabilizing the residual solid after extraction of elements. 


\subsection{Comparison Among Treatment and Disposal Technologies (In Terms of Cost)}

This section reflects the cost associated to some treatments and disposal technologies of solid analyzed in this work. The purpose is to enhance the understanding of the cost of treatment and disposal of this particular waste. Table 5 presents a comparison among treatment and disposal technologies (in terms of cost). Data were provided by calculations of authors and information provided by some Spanish solid waste treatment plants (public and private).

Table 5. Comparison among treatment and disposal technologies (in terms of cost).

\begin{tabular}{ccc}
\hline Type of Waste & Solidification/Treatment & Disposal \\
\hline \multirow{2}{*}{ Hazardous waste } & Encapsulation $90-100 € / \mathrm{t}$ & Landfilling 150-300 $€ / \mathrm{t}$ \\
\cline { 2 - 3 } & Chemical Fixation 180-200 $/ \mathrm{t}$ & Incineration 500-600 $/ \mathrm{t}$ \\
\hline Inert waste & Leaching 30-60 $€ / \mathrm{t}$ & Landfilling $50-150 € / \mathrm{t}$ \\
\hline
\end{tabular}

Chemical fixation and encapsulation were analyzed as solidification processes of hazardous waste. According to data presented in Table 5, chemical fixation is more costly than encapsulation, while encapsulation, an emerging technology, has a reasonable average cost.

With regards to disposal processes, a more cost-effective disposal process is landfilling. Incineration is more expensive than landfilling. The average costs for incineration and landfilling are $500-600 € / t$ and 50-300 $€ / t$ (depending on the type of waste).

Finally, if solid is treated to convert it into an inert waste, a treatment based on acid and basic leaching must be performed, with an estimated cost of 30-60€/t (depending on the scale of operation), however, the cost of landfilling will be reduced from 150-300€/t to approximately 50-150€/t. In addition, recovery of metals from eluate resulting from leaching could increase benefits and compensate the cost of treatment process. In this regard, the technique of precipitation, flocculation, and sedimentation is cost effective $\left(0.30-0.50 € / \mathrm{m}^{3}\right)$ for recovery metals compounds and, where additional treatment is deemed necessary, ultrafiltration has the lowest cost for metal removal.

\section{Conclusions}

In this work, acid leaching behavior of a solid mixture waste from an out of operation coal-fired power plant of Spain was analyzed. The results obtained in this work can serve as a basis for the treatment of mixed solid waste derived from power plants using coal as fuel that will be dismantled or change their activity as a consequence of abandoning the use of fossil fuels such as coal. Different leaching configurations in column systems for subsequent metals recovery and stabilization were studied and compared. Between the mineral acids studied, sulfuric acid presented a better behavior. Operation time was approximately $80 \mathrm{~min}$; after this time no significant change in concentration of metal was detected in the leachate. Leaching tests under total recirculation came to reach a constant value of $39500,2,090,000,259,110,11,275,23,538,2780$, and 19,062 ppb for Al, $\mathrm{Fe}, \mathrm{Mg}$, Mn, Ni, V, and Zn, respectively. Also, the results showed that the addition of a second stage with leachate re-set at $\mathrm{pH}$ 0.5 produces a little increase in the concentration of leachate. Then, if leaching was performed in two stages and under forced aeration, an improvement in the recovery of all studied metals was observed. For example, extraction efficiency for $\mathrm{Zn}$ increased from 25.28 to $60.03 \%$. Also, extraction yields of iron or vanadium increased up to $2.83 \%$ and $9.29 \%$, respectively. Finally, a total treatment for obtaining an inert solid was proposed. This procedure was a feasible method for totally reducing hazardous levels of the residue.

Author Contributions: Conceptualization, M.M.-L., G.B., A.P., and M.C.; methodology, G.B.; formal analysis, M.M.-L., G.B., A.P., and M.C.; experimental investigation, E.R.; writing-original draft preparation, M.M.-L.; writing-review and editing, M.M.-L. and M.C.

Funding: This research was funded by MINERA DE ÓRGIVA, S.L. 
Acknowledgments: The authors are grateful to the Minera de Órgiva, S.L., Granada, Spain for financial support, supply of materials used for experiments and approval of this work for publication. Also, authors would like to thank to Celso Amor for his helpful advice on various technical issues oriented to scale-up.

Conflicts of Interest: The authors declare no conflict of interest.

\section{References}

1. García-Gusano, D.; Iribarren, D.; Dufour, J. Is coal extension a sensible option for energy planning? A combined energy systems modeling and life cycle assessment approach. Energy Policy 2018, 114, 413-421. [CrossRef]

2. World Coal Association. Coal and Electricity. 2018. Available online: http://www.worldcoal.org/coal/uses-ofcoal/coal-electricity/ (accessed on 22 April 2019).

3. Heinrichs, H.U.; Markewitz, P. A coal phase-out in Germany-Clean, efficient and affordable? Energy Procedia 2015, 75, 2541-2547. [CrossRef]

4. Kefford, B.M.; Ballinger, B.; Schmeda-Lopez, D.R.; Greig, C.; Smart, S. The early retirement challenge for fossil fuel power plants in deep decarbonisation scenarios. Energy Policy 2018, 119, 294-306. [CrossRef]

5. Markewitz, P.; Robinius, M.; Stolten, D. The future of fossil fired power plants in Germany-A lifetime analysis. Energies 2018, 11, 1616. [CrossRef]

6. Amft, M.; Leisvik, M.; Carroll, S. Applying and adapting the Swedish regulatory system for decommissioning to nuclear power reactors-The regulator's perspective. J. Environ. Radioact. 2019, 196, 181-186. [CrossRef] [PubMed]

7. Ashworth, T.; Hooper, A.; O'Connor, B.; Miller, E.; Jarratt, A. Foamed concrete facilitates decommissioning of nuclear plant. Proc. Inst. Civ. Eng. Energy 2013, 166, 58-66. [CrossRef]

8. Goudeau, V.; Daniel, B.; Dubot, D. Mobile laboratories: An innovative and efficient solution for radiological characterization of sites under or after decommissioning. J. Environ. Radioact. 2019, 196, 194-198. [PubMed]

9. Juodis, L.; Maceika, E.; Plukis, A.; Dacquait, F.; Genin, J.-B.; Benier, G. Assessment of radioactive contamination in primary circuit of WWER-440 type reactors by computer code OSCAR for the decommissioning case. Prog. Nucl. Energy 2019, 110, 191-198. [CrossRef]

10. Kim, S.; Lee, H.Y.; Song, J.S. A study on characteristics and internal exposure evaluation of radioactive aerosols during pipe cutting in decommissioning of nuclear power plant. Nucl. Eng. Technol. 2018, 50, 1088-1098. [CrossRef]

11. Mossini, E.; Parma, G.; Rossi, F.M.; Giola, M.; Cammi, A.; Macerata, E.; Padovani, E.; Mariani, M. Monte Carlo integrated approach to radiological characterization for nuclear facilities decommissioning. Radiat. Eff. Defects Solids 2018, 173, 772-783. [CrossRef]

12. Mossini, E.; Codispoti, L.; Giola, M.; Castelli, L.; Macerata, E.; Porta, A.; Campi, F.; Mariani, M. Topsoil radiological characterisation of $\mathrm{L}-54 \mathrm{M}$ reactor surroundings preliminary to decommissioning operations. J. Environ. Radioact. 2019, 196, 187-193. [CrossRef]

13. Volk, R.; Hübner, F.; Hünlich, T.; Schultmann, F. The future of nuclear decommissioning-A worldwide market potential study. Energy Policy 2019, 124, 226-261. [CrossRef]

14. Podgorodetskii, G.S.; Gorbunov, V.B.; Agapov, E.A.; Erokhov, T.V.; Kozlova, O.N. Challenges and opportunities of utilization of ash and slag waste of tpp (thermal power plant). Part 2. Izvestiya Visshikh Uchebnykh Zavedenii. Chernaya Metallurgiya = Izvestiya. Ferr. Metall. 2018, 61, 557-563. (In Russian)

15. Kinoshita, T.; Akita, S.; Kobayashi, N.; Nii, S.; Kawaizumi, F.; Takahashi, K. Metal recovery from non-mounted printed wiring boards via hydrometallurgical processing. Hydrometallurgy 2003, 69, 73-79. [CrossRef]

16. Chauhan, G.; Jadhao, P.R.; Pant, K.K.; Nigam, K.D.P. Novel technologies and conventional processes for recovery of metals from waste electrical and electronic equipment: Challenges \& opportunities-A review. J. Environ. Chem. Eng. 2018, 6, 1288-1304.

17. Jadhav, U.U.; Hocheng, H. A review of recovery of metals from industrial waste. J. Achiev. Mater. Manuf. Eng. 2012, 54, 159-167.

18. Brunori, C.; Balzamo, S.; Morabito, R. Comparison between different leaching/extraction tests for the evaluation of metal release from fly ash. Int. J. Environ. Anal. Chem. 1999, 75, 19-31. [CrossRef]

19. Komonweeraket, K.; Cetin, B.; Aydilek, A.H.; Benson, C.H.; Edil, T.B. Effects of pH on the leaching mechanisms of elements from fly ash mixed soils. Fuel 2015, 140, 788-802. [CrossRef] 
20. Yang, S.; Wei, K.; Ma, W.; Xie, K.; Wu, J.; Lei, Y. Kinetic mechanism of aluminum removal from diamond wire sawpowder in $\mathrm{HCl}$ solution. J. Hazard. Mater. 2019, 368, 1-9. [CrossRef] [PubMed]

21. Kumar, S.; Singh, G.; Mohapatra, S.K. Leaching characteristics of heavy metal in bottom ash from indian thermal power plant. J. Sci. Ind. Res. 2017, 76, 255-258.

22. Gomes, H.I.; Funari, V.; Mayes, W.M.; Rogerson, M.; Prior, T.J. Recovery of Al, Cr and V from steel slag by bioleaching: Batch and column experiments. J. Environ. Manag. 2018, 222, 30-36. [CrossRef]

23. Ishigaki, T.; Nakanishi, A.; Tateda, M.; Ike, M.; Fujita, M. Bioleaching of metal from municipal waste incineration fly ash using a mixed culture of sulphur-oxidizing and iron-oxidizing bacteria. Chemosphere 2005, 60, 1087-1094. [CrossRef]

24. Yang, J.; Wang, Q.; Wang, Q.; Wu, T. Heavy metals extraction from municipal solid waste incineration fly ash using adapted metal tolerant Aspergillus niger. Biosour. Technol. 2008, 100, 254-260. [CrossRef] [PubMed]

25. Komonweeraket, K.; Cetin, B.; Benson, C.H.; Aydilek, A.H.; Edil, T.B. Leaching characteristics of toxic constituents from coal fly ash mixed soils under the influence of $\mathrm{pH}$. Waste Manag. 2015, 38, 174-184. [CrossRef]

26. Rivas, E.; Calero, M.; Amor, C.; Blázquez, G.; Martín-Lara, M.A.; Pérez, A. Mixed solid waste from the decommissioning of coal-fired power plants as a resource of high value metals. Process Saf. Environ. Prot. 2019, paper accepted for publication. [CrossRef]

27. Xiao, Y.; Liu, T.; Miao, Y.; Lan, T.; Liu, D. Characteristic of leaching toxicity of lead in flying ash with pretreatment effect. Chin. J. Environ. Eng. 2017, 11, 4808-4814.

28. Jayaranjan, M.L.D.; Hullebusch, E.D.; Annachhatre, A.P. Reuse options for coal fired power plant bottom ash and fly ash. Rev. Environ. Sci. Biotechnol. 2014, 13,467-486. [CrossRef]

29. Li, S.; Qin, S.; Kang, L.; Liu, J.; Wang, J.; Li, Y. An efficient approach for lithium and aluminum recovery from coal fly ash by pre-desilication and intensified acid leaching processes. Metals 2017, 7, 272. [CrossRef]

30. Chichester, D.L.; Landsberger, S. Determination of the leaching dynamics of metals from municipal solid waste incinerator fly ash using a column test. J. Air Waste Manag. Assoc. 1996, 46, 643-649. [CrossRef]

31. Zhang, F.S.; Itoh, H. Extraction of metals from municipal solid waste incinerator fly ash by hydrothermal process. J. Hazard. Mater. 2006, 136, 663-670. [CrossRef]

32. Nagib, S.; Inoue, K. Recovery of lead and zinc from fly ash generated from municipal incineration plants by means of acid and/or alkaline leaching. Hydrometallurgy 2000, 56, 269-292. [CrossRef]

33. Funari, V.; Mäkinen, J.; Salmine, J.; Braga, R.; Dinelli, E.; Revitzer, H. Metal removal from municipal solid waste incineration fly ash: A comparison between chemical leaching and bioleaching. Waste Manag. 2017, 60, 397-406. [CrossRef]

34. Wang, H.; Fan, X.; Wang, Y.; Li, W.; Zhan, Y.M.; Wu, G. Comparative leaching of six toxic metals from raw and chemically stabilized MSWI fly ash using citric acid. J. Environ. Manag. 2018, 208, 15-23. [CrossRef]

35. Ferraro, A.; Fabbricino, M.; van Hullebusch, E.D.; Esposito, G.; Pirozzi, F. Effect of soil/contamination characteristics and process operational conditions on aminopolycarboxylates enhanced soil washing for heavy metals removal: A review. Rev. Environ. Sci. Biol. 2015, 15, 111-145. [CrossRef]

36. Liu, Q.; Deng, Y.; Tang, J.; Chen, D.; Li, X.; Lin, Q.; Yin, G.; Zhang, M.; Hu, H. Potassium lignosulfonate as a washing agent for remediating lead and copper co-contaminated soils. Sci. Total Environ. 2019, 658, 836-842. [CrossRef] [PubMed]

37. Jiao, F.; Zhang, L.; Dong, Z.; Namioka, T.; Yamada, N.; Ninomiya, Y. Study on the species of heavy metals in MSW incineration fly ash and their leaching behavior. Fuel Process. Technol. 2016, 152, 108-115. [CrossRef]

38. Quina, M.J.; Bordado, J.C.M.; Quinta-Ferreira, R.M. The influence of $\mathrm{pH}$ on the leaching behaviour of inorganic components from municipal solid waste APC residues. Waste Manag. 2009, 29, 2483-2493. [CrossRef] [PubMed]

39. Gupta, L.; Kawahata, H.; Takeuchi, M.; Ohta, H.; Ono, Y. Temperature and pH Dependence of Some Metals Leaching from Fly Ash of Municipal Solid Waste. Resour. Geol. 2008, 55, 357-372. [CrossRef]

(C) 2019 by the authors. Licensee MDPI, Basel, Switzerland. This article is an open access article distributed under the terms and conditions of the Creative Commons Attribution (CC BY) license (http://creativecommons.org/licenses/by/4.0/). 